\title{
Utility of mediastinoscopy in clinical stage I lung cancers at risk for occult mediastinal nodal metastases
}

\author{
Felix G. Fernandez, MD, ${ }^{\mathrm{a}, \mathrm{b}}$ Benjamin D. Kozower, MD, MPH, ${ }^{\mathrm{c}}$ Traves D. Crabtree, MD, ${ }^{\mathrm{d}}$ \\ Seth D. Force, MD, ${ }^{\mathrm{a}}$ Christine Lau, MD ${ }^{\mathrm{c}}$ Allan Pickens, MD, ${ }^{\mathrm{a}}$ Alexander S. Krupnick, MD, \\ Nirmal Veeramachaneni, MD, ${ }^{\mathrm{e}}$ G. Alexander Patterson, MD, ${ }^{\mathrm{d}}$ David R. Jones, MD, ${ }^{\mathrm{f}}$ and \\ Bryan F. Meyers, MD, MPH ${ }^{\mathrm{d}}$
}

Objective: The prevalence of mediastinal lymph node metastases is unknown for patients with clinical N0 lung cancer who are thought to be at high risk for occult nodal metastases. Further, the utility of mediastinoscopy in these patients is unknown. We performed a prospective trial to evaluate the utility of routine cervical mediastinoscopy for patients who may be at high risk of occult nodal metastases.

Methods: From January 1, 2008, July 31, 2013, 90 patients with lung cancer with clinical stage T2N0 or T1N0 with standardized uptake value greater than 10 by positron emission tomography/computed tomography underwent routine cervical mediastinoscopy before lung resection. Biopsy of a minimum of 3 nodal stations at mediastinoscopy and a minimum of 4 nodal stations with lung resection was advised. The prevalence of nodal metastases at mediastinoscopy and lung resection was recorded.

Results: Some $64 \%$ of patients with lung cancer were male with a mean age of 67.3 years. A total of 81 patients had clinical T2N0 and 9 patients had T1N0 with standardized uptake value greater than 10. Mean tumor size was $4.3 \pm 1.7 \mathrm{~cm}$, and mean standardized uptake value was $13.5 \pm 6.8$. One patient $(1.1 \%)$ had occult metastases detected at mediastinoscopy. A total of 86 patients underwent surgical resection; 4 patients $(4.6 \%)$ were upstaged to $\mathrm{pN} 2$, and 18 patients $(21 \%$ ) were upstaged to $\mathrm{pN} 1$. Of 90 patients with clinically staged N0 lung cancer by positron emission tomography/computed tomography, $5.6 \%$ (5) were upstaged to $\mathrm{pN} 2$ and $20 \%$ (18) were upstaged to $\mathrm{pN} 1$ (total nodal upstaging $=25.6 \%$ ).

Conclusions: Mediastinoscopy seems to have limited utility in these patients with T1 and T2 clinically staged N0 by positron emission tomography/computed tomography. Selective use of mediastinoscopy is recommended, along with thorough mediastinal lymph node evaluation in all patients at the time of lung cancer resection.

(J Thorac Cardiovasc Surg 2015;149:35-42)

See related commentary on pages $43-4$.

\footnotetext{
From the Section of General Thoracic Surgery, ${ }^{a}$ Emory University School of Medicine, Atlanta, Ga; Atlanta Veterans Affairs Medical Center, ${ }^{\mathrm{b}}$ Decatur, Ga; Division of Cardiothoracic Surgery, ${ }^{\mathrm{c}}$ University of Virginia School of Medicine, Charlottesville, Va; Section of General Thoracic Surgery, ${ }^{\mathrm{d}}$ Washington University School of Medicine, St Louis, Mo; Cardiothoracic Surgery, ${ }^{\mathrm{e}}$ University of Kansas Medical Center, Kansas City, Mo; and Thoracic Surgery, ${ }^{\mathrm{f}}$ Memorial Sloan Kettering Cancer Center, New York, NY.

Disclosures: Traves D. Crabtree reports consulting and lecture fees from Ethicon Endosurgery. Bryan F. Meyers reports consulting fees from Ethicon Endosurgery and Varian Medical Systems. All other authors have nothing to disclose with regard to commercial support.

Read at the 94th Annual Meeting of The American Association for Thoracic Surgery, Toronto, Ontario, Canada, April 26-30, 2014.

Received for publication April 9, 2014; revisions received Aug 15, 2014; accepted for publication Aug 20, 2014; available ahead of print Oct 23, 2014.

Address for reprints: Felix G. Fernandez, MD, The Emory Clinic, 1365 Clifton Rd NE, Suite A2214, Atlanta, GA 30322 (E-mail: felix.fernandez@ emoryhealthcare.org).

0022-5223/\$0.00

Published by Elsevier Inc. on behalf of The American Association for Thoracic Surgery

http://dx.doi.org/10.1016/j.jtcvs.2014.08.075
}

Supplemental material is available online.

Patients with non-small cell lung cancer (NSCLC) with mediastinal lymph node metastases are typically not considered primary surgical candidates but are offered definitive radiation and chemotherapy or induction therapy followed by surgery. Mediastinoscopy is the established standard for diagnosis of mediastinal lymph node metastases in NSCLC. ${ }^{1}$ More frequently, surgeons are willing to accept results of noninvasive mediastinal staging with F18 fluorodeoxyglucose positron emission tomography (PET) and computed tomography (CT) and skip invasive staging with mediastinoscopy. ${ }^{2}$

Patients with clinical T1N0 NSCLC staged with PET/CT appear to benefit little from invasive mediastinal lymph node staging via mediastinoscopy. However, larger tumor size, higher maximum standardized uptake value (SUV) of the primary tumor, and tumor histology of adenocarcinoma may predict occult mediastinal lymph node 


$$
\begin{array}{ll}
\text { Abbreviations and Acronyms } \\
\text { CT } & =\text { computed tomography } \\
\text { EBUS-TBNA = } & \text { endobronchial ultrasound-guided } \\
& \text { transbronchial needle aspiration } \\
\text { NPV } & =\text { negative predictive value } \\
\text { NSCLC } & =\text { non-small cell lung cancer } \\
\text { PET } & =\text { positron emission tomography } \\
\text { SUV } & =\text { standardized uptake value } \\
\text { VATS } & = \\
& \text { video-assisted thoracoscopic } \\
& \text { surgery }
\end{array}
$$

metastases after PET/CT staging. ${ }^{3-11}$ One series reports a rate of $11.7 \% \mathrm{~N} 2$ metastases in 137 patients with $\mathrm{T} 2-3$ tumors after PET/CT staging. ${ }^{12}$ In addition, Cerfolio and colleagues $^{13}$ found that patients clinically staged as T1N0M0 with a maximum SUV in the primary tumor greater than 10 also have a higher prevalence of mediastinal nodal metastases.

A prior decision analysis reported by one of our authors (BFM) suggests that there is little benefit to performing mediastinoscopy in patients with clinical stage I NSCLC after PET/CT staging. ${ }^{14}$ With a prevalence of clinically occult nodal metastases of $5.6 \%$, mediastinoscopy had a low sensitivity, was expensive, and added little life expectancy. However, if the prevalence of $\mathrm{N} 2$ disease were to exceed $10 \%$, it was predicted that mediastinoscopy would lengthen life at a cost of less than $\$ 100,000$ per life-year gained.

The objective of this study was to prospectively determine the prevalence of mediastinal lymph node metastases detectable by mediastinoscopy in patients with clinically staged T2NOM0 NSCLC by PET/CT, as well as patients with clinically staged T1N0M0 NSCLC with a high maximum SUV of the primary tumor. We hypothesize that the prevalence of mediastinal lymph node metastases detectable by cervical mediastinoscopy after PET/CT staging is sufficiently low $(<10 \%)$ to not support the routine use of this test in the study population.

\section{MATERIALS AND METHODS}

The study design is a prospective observational cohort study. From January 1, 2008, to July 31, 2013, patients with biopsy-proven or presumptive lung cancer clinical stage $\mathrm{T} 2 \mathrm{~N} 0$ or T1N0 with a maximum SUV greater than 10 by PET/CT scans were prospectively enrolled after informed consent to undergo routine cervical mediastinoscopy for staging before planned lung resection. Patients were enrolled at 5 institutions: Washington University in St Louis (St Louis, Mo), University of Virginia (Charlottesville, Va), Emory University (Atlanta, Ga), Atlanta Veterans Affairs Medical Center (Decatur, Ga), and University of North Carolina (Chapel Hill, NC). Surgeons at these participating centers have a history of academic collaboration, which led to the organization of this study group. Approval to conduct this study was obtained by the institutional review board at each participating institution, and the study was registered with clinicaltrials.gov (NCT01146366).

\section{Inclusion Criteria}

Patients must have had proven or suspected clinical stage T2N0 and select T1N0 primary lung cancers. Patients with clinical stage IA (T1NOM0) were allowed participation if the maximum SUV of the primary tumor was greater than 10. Clinical stage IB (T2NOM0) must have been met by size criterion only $(>3 \mathrm{~cm})$. Enrollment criteria were determined on the basis of prior literature. ${ }^{13,14}$ Clinical tumor stage was classified according to the AJCC Cancer Staging Manual, 6th edition, given that the study began in $2008 .{ }^{15}$ Final pathologic staging is classified according to the AJCC Cancer Staging Manual, 7th edition. ${ }^{16}$ Retrospectively, 4 patients enrolled with T2 tumors under the AJCC Cancer Staging Manual, 6th edition, reclassify as T3 under the 7th edition staging system. Preoperative staging on all patients was required to be performed with a CT scan of the chest and upper abdomen and an F-18 fluorodeoxyglucose-PET scan to confirm clinical stage I status. One of the studies had to be completed within 60 days of enrollment. No specific standardization was required for the PET or CT scans, and studies from outside institutions were accepted. A clinically positive lymph node was considered to be any lymph node greater than $1 \mathrm{~cm}$ in short axis on a CT scan or with metabolic uptake greater than the reference body metabolic activity on PET. Magnetic resonance imaging of the brain was not required for enrollment.

Patients must have been considered surgical candidates for at least a lobectomy or other anatomic resection. For performance status, patients must have had an Eastern Cooperative Oncology Group or Zubrod score of 0,1 , or 2 . Patients could not have undergone previous invasive mediastinal staging for this cancer or have had a prior tracheostomy.

\section{Performance of Mediastinoscopy and Pulmonary Resection}

For all patients undergoing mediastinoscopy, biopsy of at least 3 different lymph node stations in the mediastinum from levels $2 \mathrm{R}, 4 \mathrm{R}, 7$, $2 \mathrm{~L}$, and $4 \mathrm{~L}$ was advised. If $\mathrm{N} 2$ disease was detected, treatment was not specified. If mediastinoscopy was negative, patients underwent thoracotomy or video-assisted thoracoscopic surgery (VATS) for intended anatomic pulmonary resection of the primary tumor and mediastinal lymph node systematic sampling or mediastinal lymph node dissection. Sampling of at least 4 nodal stations was advised on the basis of side of resection. For right-sided tumors, nodal stations included 2R, 4R, 7, 9R, and 10R. For left-sided tumors, nodal stations included 5, 6, 7, 9L, and 10L. The remainder of care was not specified. Patients found not to have primary lung cancer were not included in the final analysis.

The technique of mediastinoscopy was consistent across study sites. A small low transverse cervical incision was used. The strap muscles were separated along their midline raphe. The pretracheal fascia was incised, and blunt dissection was performed to separate the trachea from surrounding mediastinal structures. A mediastinoscope was inserted into the cervical wound, and use of conventional or video-assisted mediastinoscopy was not specified. Blunt dissection with a suction device was used to examine 5 mediastinal lymph node stations: $2 \mathrm{R}, 2 \mathrm{~L}, 4 \mathrm{R}, 4 \mathrm{~L}$, and 7. Lymph nodes were sampled with biopsy forceps.

\section{Patients}

A flow diagram of patients enrolled in the study is presented in Figure 1. A total of 99 patients were enrolled and underwent mediastinoscopy before planned resection of biopsy proven or suspected primary lung cancer (Figure 1). Only 1 patient (1\%) had occult lymph node metastases detected at the time of mediastinoscopy. This patient with a left upper lobe lung cancer had a $4 \mathrm{~L}$ metastasis detected and was treated with definitive radiation and chemotherapy. Another patient with lung cancer who had a negative mediastinoscopy became too frail to undergo pulmonary resection. A total of 97 patients underwent thoracotomy or VATS for planned pulmonary resection. Two patients had pleural metastases 


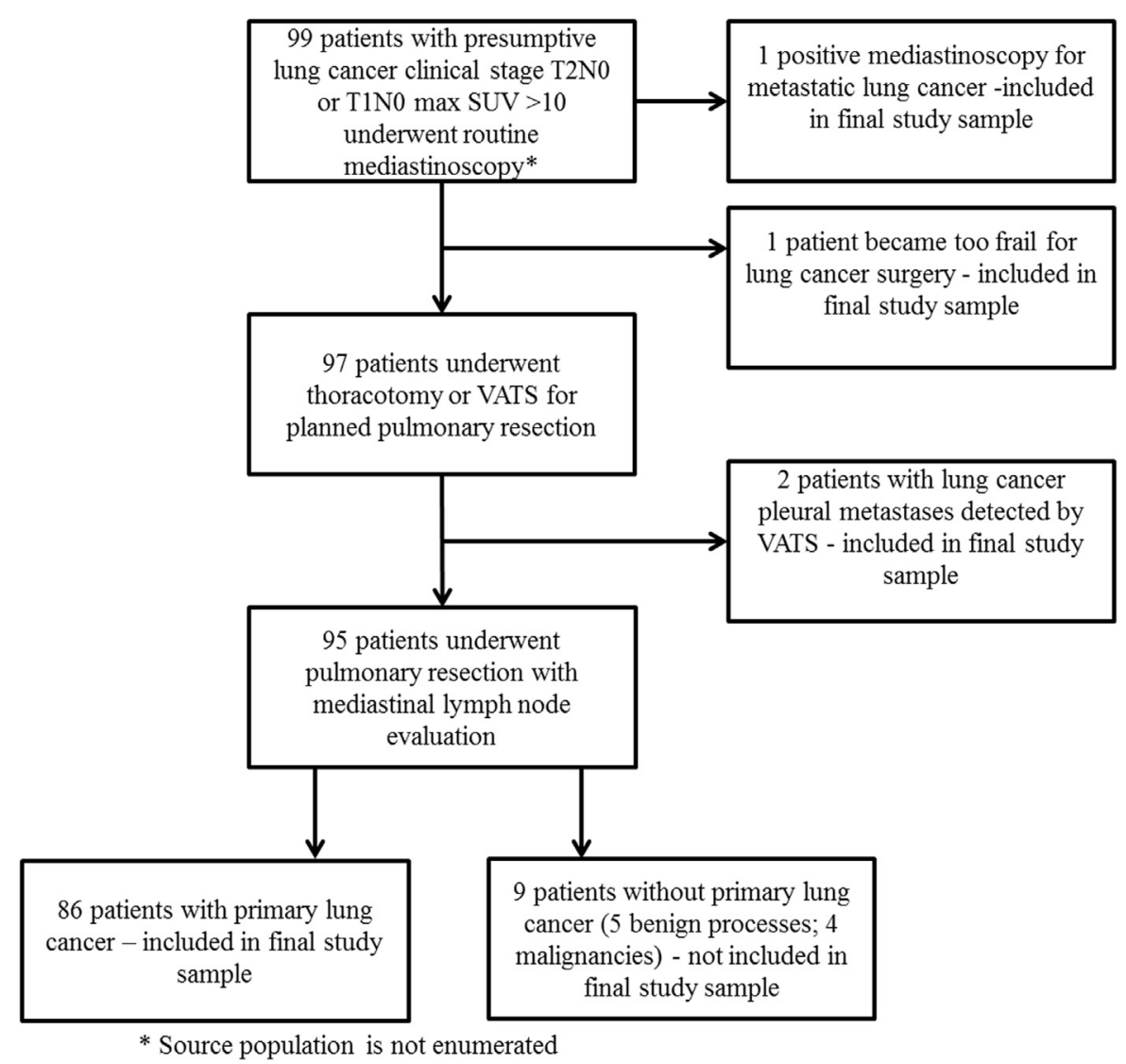

FIGURE 1. Flow diagram demonstrating enrollment, allocation, and analysis of patients in this prospective observational cohort study. SUV, Standardized uptake value; VATS, video-assisted thoracoscopic surgery.

diagnosed by VATS, and resection was aborted. Pulmonary resection was performed in 95 patients, and 86 of these patients had primary lung cancer on final pathology. Benign disease was confirmed in 5 patients (ie, necrotizing granuloma, organizing pneumonia), and 4 patients had non-lung cancer malignancies (1 each: thymoma, choriocarcinoma, metastatic breast adenocarcinoma, and B-cell lymphoma). Suspicion of primary lung cancer remained in these 9 patients after mediastinoscopy; therefore, VATS or thoracotomy was performed. In total, 90 patients ( $91 \%$ of the enrolled study population) had primary lung cancer and make up the study sample.

\section{Analysis}

The primary outcome measure for this study was the prevalence of occult mediastinal lymph node metastases in the study population with primary lung cancer. This represents the fraction of patients with lung cancer with mediastinal lymph node metastases detected by mediastinoscopy or systematic sampling/dissection. Secondary outcome measures included (1) the sensitivity and negative predictive value (NPV) of cervical mediastinoscopy for detection of clinically occult N2 metastases after PET/ CT and (2) complications from cervical mediastinoscopy and thoracotomy/ VATS with mediastinal lymph node sampling. Major morbidities were defined as per the Society of Thoracic Surgeons General Thoracic Surgery Database risk models for pulmonary resection. ${ }^{17}$

Because the previous cost-effectiveness analysis identified a threshold of interest at a prevalence of $10 \%$, we aimed to enroll 96 patients with NSCLC to allow the 2 -sided confidence intervals to be approximately $5 \%$ on either side of the observed prevalence (ie, alpha $=0.1$ ). With a sample size of 96 , a 2-sided $90.0 \%$ confidence interval extends 0.050 from the observed proportion for an expected proportion of 0.100 . To enroll 96 patients with cancer, we planned to enroll approximately 15 patients more than this to account for benign disease and other tumors. Because of time and funding constraints, we terminated the study after 99 of 111 intended patients were enrolled. The clinical research unit of the Division of Cardiothoracic Surgery at Washington University served as the data analysis center for this study. Data analysis was performed with SPSS 13.0 for Windows software (SPSS Inc, Chicago, Ill). All data are presented as means with standard deviations or counts with percentages. A chi-square goodness-offit test was used to compare the prevalence of $\mathrm{N} 2$ nodal metastases in the study population with the a priori determined clinically significant rate of $10 \%$.

\section{RESULTS}

Clinical data from the 90 patients with primary lung cancer who underwent mediastinoscopy are presented in Table 1 . The majority of patients met study inclusion criteria by tumor size (T2) rather than maximum SUV criteria. One patient $(1.1 \%)$ had occult lung cancer lymph node metastases detected with mediastinoscopy, as mentioned earlier. Of 275 clinically negative (cN0) mediastinal lymph node stations evaluated with mediastinoscopy, occult metastatic lung cancer $(\mathrm{pN} 2)$ was identified in only 1 lymph node $(0.4 \%)$ (Table 2). There were 57 right- and 33 left-sided tumors. For right-sided tumors, N2 nodes were sampled in 
TABLE 1. Clinical characteristics of study population

\begin{tabular}{|c|c|}
\hline Variable & $\begin{array}{l}\text { Mean } \pm \text { standard deviation } \\
\text { or counts with percentage }\end{array}$ \\
\hline \multicolumn{2}{|l|}{ Gender } \\
\hline Male & $58(64 \%)$ \\
\hline Age $(y)$ & $67.3 \pm 11.4$ \\
\hline \multicolumn{2}{|l|}{ Clinical stage } \\
\hline $\mathrm{T} 2 \mathrm{~N} 0 *$ & $81(90 \%)$ \\
\hline T1N0 SUV maximum $\geq 10$ & $9(10 \%)$ \\
\hline Tumor size $(\mathrm{cm})$ & $4.3 \pm 1.7($ range, $1.3-12)$ \\
\hline SUV maximum & $13.5 \pm 6.8($ range, $1.2-40.3)$ \\
\hline $\begin{array}{l}\text { No. of nodal stations evaluated at } \\
\text { mediastinoscopy }\end{array}$ & $3.1 \pm 0.7$ \\
\hline \multicolumn{2}{|l|}{ Approach to pulmonary resection } \\
\hline Thoracotomy & $48(53 \%)$ \\
\hline VATS & $40(44 \%)$ \\
\hline None & $2(2 \%)$ \\
\hline \multicolumn{2}{|l|}{ Extent of lung resection $(\mathrm{n}=86) \dagger$} \\
\hline Segmentectomy & $5(6 \%)$ \\
\hline Lobectomy & $69(80 \%)$ \\
\hline Bilobectomy & $4(5 \%)$ \\
\hline Sleeve lobectomy & $2(2 \%)$ \\
\hline Pneumonectomy & $6(7 \%)$ \\
\hline \multicolumn{2}{|c|}{ Extent of lymph node evaluation $(\mathrm{n}=86)^{*}$} \\
\hline Systematic sampling & $46(53 \%)$ \\
\hline Lymph node dissection & $40(47 \%)$ \\
\hline \multicolumn{2}{|l|}{ Histology } \\
\hline Squamous cell & $38(42 \%)$ \\
\hline Adenocarcinoma & $35(39 \%)$ \\
\hline Large cell & $6(7 \%)$ \\
\hline Other & $12(13 \%)$ \\
\hline \multicolumn{2}{|c|}{$\begin{array}{l}\text { Pathologic stage (AJCC Cancer Staging } \\
\qquad \text { Manual, } 7 \text { th }^{16} \mathrm{ed}^{16} \text { ) }\end{array}$} \\
\hline IA & $13(14 \%)$ \\
\hline IB & $37(41 \%)$ \\
\hline IIA & $6(7 \%)$ \\
\hline IIB & $23(26 \%)$ \\
\hline IIIA & $9(10 \%)$ \\
\hline IV & $2(2 \%)$ \\
\hline
\end{tabular}

AJCC, American Joint Committee on Cancer; SUV, standardized uptake value; VATS, video-assisted thoracoscopic surgery. *According to the AJCC Cancer Staging Manual, 6th ed, ${ }^{15}$ used for study enrollment. Four patients had T3 tumors $(\geq 7 \mathrm{~cm}$ in size) according to the AJCC Cancer Staging Manual, 7 th ed, ${ }^{16}$ staging. $†$ Two patients had occult M1 disease detect at the time of VATS, and 2 patients did not undergo thoracotomy or VATS.

$100 \%$ of patients and $\mathrm{N} 3$ nodes were sampled in $44 \%$ of patients (25/57) with mediastinoscopy. For left-sided tumors, $\mathrm{N} 2$ nodes were sampled in $100 \%$ of patients and N3 nodes were sampled in $45 \%$ of patients (15/33) with mediastinoscopy. An anatomic lobectomy was the most common pulmonary resection performed for lung cancer.

Of 86 patients who underwent pulmonary resection for lung cancer, $4(4.6 \%)$ were found to have occult mediastinal lymph node metastases and upstaged to $\mathrm{pN} 2$ at the time of lung cancer resection (Table 2). This results in an overall rate of $5.6 \%$ upstaging to $\mathrm{pN} 2$ in the entire study population when you include the 1 patient with positive mediastinoscopy (5/99 or $5 \%$ including patients with benign disease). Details of patients upstaged to N2 are shown in Table 3. As shown in Table 4, 18 additional patients $(21 \%)$ were upstaged to $\mathrm{pN} 1$ at the time of lung resection. Therefore, the total combined N1 and N2 nodal upstaging was $25.6 \%$ in both the entire study population (23/90) and the subgroup undergoing lung cancer resection (22/86). An average of 3.4 of mediastinal and hilar nodal stations were sampled by VATS versus 3.4 with thoracotomy. N2 upstaging was $2.6 \%$ (1/38) with VATS and $6.2 \%(3 / 48)$ with thoracotomy. The prevalence of $\mathrm{N} 2$ disease in patients clinically staged T1 with an SUV greater than 10 was $11 \%(1 / 9)$ and $4.9 \%$ (4/81) for T2. The mean SUV in the T1 cases was 14.2 and 13.4 in the T2 cases.

Of an intended 96 patients, a total of 90 patients with lung cancer were enrolled in this prospective study. On the basis of prior data, we had set $10 \%$ as a clinically important rate of detection of occult $\mathrm{N} 2$ nodal metastases. We observed a rate of $4.4 \%(4 / 90 ; 90 \%$ confidence interval, $0.1-0.8)$ of occult metastases in lymph node stations accessible by mediastinoscopy, excluding the 1 station 5 metastasis, which is typically not assessed with mediastinoscopy. With a preset alpha of 0.1 , this proportion was significantly lower than the predetermined rate of $10 \%(P=.079)$ when examined with a chi-square goodness-of-fit test.

The NPV of a PET/CT scan for mediastinal lymph node metastases was $94.2 \%$ (82/87). The addition of mediastinoscopy to PET/CT staging increased the NPV of mediastinal staging to $95.3 \%$ (82/86), an increase of only $1 \%$. After clinical staging with PET/CT, the sensitivity of mediastinoscopy to detect occult mediastinal disease was $25 \%$ (1/4). The NPV of PET/CT was $73.5 \%(64 / 87)$ for all lymph node metastases (N1 and N2) and 79.1\% (68/86) for only N1 lymph nodes.

Of 99 mediastinoscopies, there were no mortalities and only 2 complications ( $2 \%$ ), both pneumothoraces managed with pleural drainage. Complications associated with pulmonary resection are shown in detail in Table E1. The perioperative mortality rate was $2.1 \%$ (2/95), with a major morbidity rate of $11.6 \%$ (11/95) and an overall complication rate of $37.9 \%(36 / 95)$.

\section{DISCUSSION}

The prevalence of occult mediastinal lymph node metastases in patients with lung cancer in this study clinically staged as T2N0 or T1N0 with a maximum SUV greater than 10 by PET/CT was low at $5.6 \%$. The routine implementation of cervical mediastinoscopy detected only 1 patient with occult $\mathrm{N} 2$ disease. Therefore, routine mediastinoscopy does not seem to add much benefit for this study population after noninvasive staging with PET/CT.

In patients with clinical stage I NSCLC by CT staging alone, the reported prevalence of mediastinal lymph node 
TABLE 2. Mediastinal lymph node evaluation and upstaging during mediastinoscopy and lung cancer resection

\begin{tabular}{lccc}
\hline $\begin{array}{c}\text { Mediastinal } \\
\text { nodal stations }\end{array}$ & $\begin{array}{c}\text { No. of patients with nodal station } \\
\text { sampled at mediastinoscopy }(\mathbf{n = 9 0 )}\end{array}$ & $\begin{array}{c}\text { No. of nodal metastases detected by } \\
\text { mediastinoscopy }\end{array}$ & $\begin{array}{c}\text { No. of nodal metastases detected at } \\
\text { thoracotomy or VATS* }\end{array}$ \\
\hline 2R & 50 & 0 & 0 \\
2L & 1 & 0 & 0 \\
$4 \mathrm{R}$ & 86 & 0 & 1 \\
$4 \mathrm{~L}$ & 51 & 1 & 0 \\
7 & 87 & 0 & 2 \\
\hline
\end{tabular}

VATS, Video-assisted thoracoscopic surgery. *One additional patient was upstaged to pN2 by detection of occult metastases at station 5 , making the total number of patients upstaged to pN2 5 as $90(5.6 \%)$. Only 86 patients underwent lymph node staging by thoracotomy or VATS.

metastasis ranges from $6 \%$ to $21 \% .{ }^{18-20}$ In patients clinically staged with N0 by PET or PET/CT, the prevalence of mediastinal metastases has been reported to range from $3.7 \%$ to $11.7 \% .{ }^{13,14,21,22}$ Wang and colleagues ${ }^{3}$ have found that the NPV of PET/CT for N2 metastases was 93\% (94\% for T1 and $89 \%$ for T2). Prior studies have shown that larger primary tumor size predicts occult $\mathrm{N} 2$ disease. ${ }^{6,7}$ In addition, the presence of occult mediastinal nodal metastases has been correlated with higher maximum SUV of the primary tumor. $^{4,6,9,11,13}$ Adenocarcinoma histology has been associated with occult $\mathrm{N} 2$ disease, but central location of the primary tumor has not. ${ }^{6,8,10,11}$ The rate of $5.6 \% \mathrm{~N} 2$ metastases in our study in patients with clinically staged T2N0 or T1N0 maximum SUV greater than 10 is in agreement with these retrospective data.

Mediastinoscopy has been the standard for mediastinal lymph node staging, with a sensitivity of $90 \%$ to $95 \%$. $^{1,23,24}$ After PET/CT, the sensitivity of mediastinoscopy was $25 \%$ in our study. This lower sensitivity for mediastinoscopy in the setting of a clinically negative $\mathrm{PET} / \mathrm{CT}$ is not unexpected given the high sensitivity of the first screening test, as demonstrated by Gould and colleagues. ${ }^{25}$ The NPV of $95.3 \%$ for mediastinoscopy after $\mathrm{PET} / \mathrm{CT}$ is a marginal contribution compared with the NPV of $94.2 \%$ seen with PET/CT alone.

Despite the low rate of $\mathrm{N} 2$ nodal upstaging in our study (5.6\%), $20 \%$ of patients were upstaged to N1. The total rate of nodal upstaging was $25.6 \%$. This is higher than rates of up to $15 \%$ nodal upstaging reported for T1 tumors. ${ }^{7,26}$ Patients with lung cancer with lymph node metastases may derive a survival benefit from the administration of adjuvant chemotherapy. ${ }^{27,28}$ Therefore, whether or not invasive mediastinal staging is pursued with a mediastinoscopy, a thorough mediastinal and hilar lymph node evaluation is essential at the time of lung cancer resection. A benefit for mediastinal lymph node dissection over systematic nodal sampling has not been demonstrated, and both strategies were commonly used by surgeons in our study. ${ }^{29}$ Neither strategy was associated with increased nodal upstaging. The data on occult N1 disease are most important in considering nonsurgical modalities, such as stereotactic body radiation therapy or radiofrequency ablation, for the treatment of lung cancer in otherwise operable patients. The ability to render a patient free of disease by removing all affected N1 nodes may be lost with nonoperative strategies.

Two study patients had negative mediastinoscopy and then underwent a pneumonectomy. Both had N2 metastases detected with pulmonary resection. Mediastinoscopy may be limited at evaluating the inferior portions of the level 7 lymph node. ${ }^{4}$ Endoscopic ultrasonography with fine-needle aspiration may improve the sensitivity of staging at station 7 , although its yield in patients with clinical N0 lung cancer is likely limited.

In our study, mediastinoscopy was more reliable in sampling certain lymph node stations $(4 \mathrm{R}, 96 \%$ and 7 , $97 \%)$ than others $(2 \mathrm{R}, 55 \% ; 2 \mathrm{~L}, 1 \%$; and $4 \mathrm{~L}, 57 \%)$. This compares favorably to other series, including a series of 1970 mediastinoscopies recently reported by Wei and colleagues. ${ }^{30}$ In comparison, in our series, a greater mean number of nodal stations were sampled with mediastinoscopy (3.1 vs 2.4) and a greater percentage of patients had stations $7(97 \%$ vs $45 \%)$ and $4 \mathrm{~L}$ sampled (57\% vs $22 \%)$, although sampling of station $2 \mathrm{R}$ was inferior $(55 \%$ vs $77 \%$ ). Therefore, the quality of mediastinoscopy represents a strength of our study. Video-assisted mediastinal lymphadenectomy and transcervical extended mediastinal lymphadenectomy techniques have been shown to outperform standard cervical mediastinoscopy. ${ }^{31,32}$ Both

TABLE 3. Tumor characteristics of patients with occult mediastinal lymph node metastases

\begin{tabular}{llccc}
\hline Lymph node station + & \multicolumn{1}{c}{ Procedure } & Tumor size on CT $(\mathbf{c m})$ & Maximum SUV on PET & Histology \\
\hline 5 & Left upper lobectomy & 3.2 & 8.9 & Adenocarcinoma \\
$4 \mathrm{~L}$ & Mediastinoscopy & 3.3 & 9.7 & Squamous cell \\
7 & Left Pneumonectomy & 4.1 & 16.1 & Squamous cell \\
7 & Right pneumonectomy & 3.1 & 8.9 & Adenocarcinoma \\
$4 \mathrm{R}$ & Right upper lobectomy & 2.8 & 10.2 & Adenosquamous \\
\hline
\end{tabular}

$C T$, Computed tomography; $P E T$, positron emission tomography; SUV, standardized uptake value. 
TABLE 4. Nodal evaluation and upstaging during thoracotomy or video-assisted thoracoscopic surgery

\begin{tabular}{lcc}
\hline Lymph node stations & $\begin{array}{c}\text { No. of patients with } \\
\text { nodal station } \\
\text { sampled }(\mathbf{n}=\mathbf{8 6})\end{array}$ & $\begin{array}{c}\text { No. of nodal } \\
\text { metastases } \\
\text { detected }\end{array}$ \\
\hline $2 \mathrm{R}$ & 5 & 0 \\
$2 \mathrm{~L}$ & 1 & 0 \\
$4 \mathrm{R}$ & 40 & 1 \\
$4 \mathrm{~L}$ & 3 & 0 \\
5 & 26 & 1 \\
6 & 8 & 0 \\
7 & 63 & 2 \\
8 & 0 & 0 \\
9 & 62 & 0 \\
10R & 48 & 2 \\
10L & 26 & 2 \\
Bronchopulmonary (11-14) & 74 & 14 \\
\hline
\end{tabular}

techniques are associated with higher rates of recurrent laryngeal nerve injury $(2.5 \%$ to $3.4 \%$ in the largest series), making them less appealing in patients with a clinically negative mediastinum.

As the accuracy of PET/CT mediastinal staging in patients with lung cancer has become more recognized, the use of mediastinoscopy has decreased in patients with clinical stage I disease. ${ }^{33}$ Endobronchial ultrasoundguided transbronchial needle aspiration (EBUS-TBNA) represents a less-invasive option for mediastinal staging in lieu of mediastinoscopy. In a prospective trial, Yasufuku and colleagues $^{34}$ demonstrated that EBUS-TBNA, performed in a rigorous fashion, and mediastinoscopy have excellent agreement in staging the mediastinum. However, it is not expected that EBUS-TBNA would perform better than mediastinoscopy in the detection of occult N2 nodal disease. Therefore, we believe the findings from this study are generalizable to all invasive mediastinal lymph node staging strategies. EBUS was not used by surgeons in this study for staging the mediastinum in patients who clinically had N0.

\section{Study Limitations}

Our study has limitations that need to be appreciated when considering the impact of its findings. For preoperative staging, we accepted integrated PET/CT scans and also separately performed PET and CT. We also accepted PET/CT scans performed at outside facilities, and imaging studies were not centrally reviewed. This protocol was chosen to reflect a pragmatic trial of what actually happens in clinical practice. Of note, inclusion of this scanning protocol would be more likely to lead to understaging of tumors and result in a higher rate of detection of occult $\mathrm{N} 2$ metastases. In addition, calculation of SUV is subject to variation across centers, scanners, and interpreting physicians. This may have led to misclassification of some tumors as having a maximum SUV greater than 10 . We also note that it took 5 years to complete this investigation. This study was organized without the benefit of funding or support from a cooperative group, leading to slower enrollment.

\section{CONCLUSIONS}

The detection of occult mediastinal lymph node metastases is uncommon in patients with clinical stage T2NO or T1N0 lung cancer with maximum SUV greater than 10 after PET/CT staging. The routine application of mediastinoscopy in this population does not greatly increase the NPV of a PET/CT and has poor sensitivity as a screening test. Therefore, the routine use of mediastinoscopy, or other invasive mediastinal staging modality, in this group of patients is not supported by data. However, selective use of mediastinoscopy is advised. For instance, mediastinoscopy may be of significant value in a high-risk operative patient or a patient requiring an extensive pulmonary resection. Future studies should focus on identifying predictors of occult mediastinal lymph node metastases, such as tumor biology. Whether or not invasive mediastinal staging is undertaken, a thorough mediastinal and hilar lymph node evaluation is critical, given that frequent nodal upstaging is observed.

\section{References}

1. Hammoud Z, Anderson RC, Meyers BF, Guthrie TJ, Roper CL, Cooper JD, et al. The current role of mediastinoscopy in the evaluation of thoracic disease. $J$ Thorac Cardiovasc Surg. 1999;118:894-9.

2. Vyas KS, Davenport DL, Ferraris VA, Saha SP. Mediastinoscopy: trends and practice patterns in the United States. South Med J. 2013;106:539-44.

3. Wang J, Welch K, Wang L, Kong FM. Negative predictive value of positron emission tomography and computed tomography for stage T1-2N0 non-small cell lung cancer: a meta-analysis. Clin Lung Cancer. 2012;13:81-9.

4. Cerfolio RJ, Bryant AS, Ojha B, Eloubeidi M. Improving the inaccuracies of clinical staging of patients with NSCLC: a prospective trial. Ann Thorac Surg. 2005;80:1207-13.

5. Kim BT, Lee KS, Shim SS, Choi JY, Kwon OJ, Kim H, et al. Stage T1 non-small cell lung cancer: preoperative mediastinal nodal staging with integrated FDG PET/CT - a prospective study. Radiology. 2006;241:501-9.

6. Lee PC, Port JL, Korst RJ, Liss Y, Meherally DN, Altorki NK. Risk factors for occult mediastinal metastases in clinical stage I non-small cell lung cancer. Ann Thorac Surg. 2007:84:177-81.

7. Veeramachaneni NK, Battafarano RJ, Meyers BF, Zoole JB, Patterson GA. Risk factors for occult nodal metastasis in clinical T1N0 lung cancer: a negative impact on survival. Eur J Cardiothorac Surg. 2008;33:466-9.

8. Herth FJ, Eberhardt R, Krasnik M, Ernst A. Endobronchial ultrasound-guided transbronchial needle aspiration of lymph nodes in the radiologically and positron emission tomography-normal mediastinum in patients with lung cancer. Chest. 2008;133:887-91.

9. Maeda R, Isowa N, Onuma H, Miura H, Harada T, Touge H, et al. The maximum standardized 18F-fluorodeoxyglucose uptake on positron emission tomography predicts lymph node metastasis and invasiveness in clinical stage IA non-small cell lung cancer. Interact Cardiovasc Thorac Surg. 2009;9:79-82.

10. Gómez-Caro A, Garcia S, Reguart N, Arguis P, Sanchez M, Gimferrer JM, et al. Incidence of occult mediastinal node involvement in cNO non-small-cell lung cancer patients after negative uptake of positron emission tomography/computed tomography scan. Eur J Cardiothorac Surg. 2010;37:1168-74.

11. Park HK, Jeon K, Koh WJ, Suh GY, Kim H, Kwon OJ, et al. Occult nodal metastasis in patients with non-small cell lung cancer at clinical stage IA by PET/CT. Respirology. 2010;15:1179-84.

12. Gonzalez-Stawinski GV, Lemaire A, Merchant F, O'Halloran E, Coleman RE, Harpole DH, et al. A comparative analysis of positron emission tomography 
and mediastinoscopy in staging non-small cell lung cancer. J Thorac Cardiovasc Surg. 2003;126:1900-5.

13. Cerfolio RJ, Bryant AS, Ohja B, Bartolucci AA. The maximum standardized uptake values on positron emission tomography of a non-small cell lung cancer predict stage, recurrence, and survival. J Thorac Cardiovasc Surg. 2005;130: 151-9.

14. Meyers BF, Haddad F, Siegel BA, Zoole JB, Battafarano RJ, Veeramachaneni N, et al. Cost-effectiveness of routine mediastinoscopy in computed tomographyand positron emission tomography-screened patients with stage I lung cancer. J Thorac Cardiovasc Surg. 2006;131:822-9.

15. Greene FL, Page DL, Fleming ID, Fritz A, Balch CM, Haller DG, et al; eds. AJCC Cancer Staging Manual. 6th ed. New York: Springer-Verlag; 2002.

16. Edge SB, Byrd DR, Compton CC, Fritz AG, Greene FL, Trotti A, eds. AJCC Cancer Staging Manual. 7th ed. New York, NY: Springer; 2010.

17. Kozower BD, Sheng S, O’Brien SM, Liptay MJ, Lau CL, Jones DR, et al. STS database risk models: predictors of mortality and major morbidity for lung cancer resection. Ann Thorac Surg. 2010;90:875-83.

18. Choi YS, Shim YM, Kim J, Kim K. Mediastinoscopy in patients with clinical stage I non-small cell lung cancer. Ann Thorac Surg. 2003;75:364-6.

19. Seely J, Mayo J, Miller R, Muller NL. T1 lung cancer: prevalence of mediastinal nodal metastases and diagnostic accuracy of CT. Radiology. 1993:186:129-32.

20. Defranchi SA, Cassivi SD, Nichols FC, Allen MS, Shen KR, Deschamps C, et al. N2 disease in T1 non-small cell lung cancer. Ann Thorac Surg. 2009;88:924-8.

21. van Tinteren H, Hoekstra OS, Smit EF, van den Bergh JH, Schreurs AJ, Stallaert RA, et al. Effectiveness of positron emission tomography in the preoperative assessment of patients with suspected non-small cell lung cancer: the PLUS multicentre randomised trial. Lancet. 2002;359:1388-93.

22. Vesselle H, Pugsley JM, Vallières E, Wood DE. The impact of fluorodeoxyglucose F 18 positron-emission tomography on the surgical staging of non-small cell lung cancer. J Thorac Cardiovasc Surg. 2002;124:511-9.

23. Luke WP, Pearson FG, Todd TR, Patterson GA, Cooper JD. Prospective evaluation of mediastinoscopy for evaluation of carcinoma of the lung. J Thorac Cardiovasc Surg. 1986;91:53-6.

24. Cybulsky IJ, Bennett WF. Mediastinoscopy as a routine outpatient procedure. Ann Thorac Surg. 1994;58:176-8.

25. Gould MK, Kuschner WG, Rydzak CE, Maclean CC, Demas AN, Shigemitsu H, et al. Test performance of positron emission tomography and computed tomography for mediastinal staging in patients with non small cell lung cancer. Ann Intern Med. 2003;139:879-92.

26. Stiles BM, Servais EL, Lee PC, Port JL, Paul S, Altorki NK. Point: Clinical stage IA non-small cell lung cancer determined by computed tomography and positron emission tomography is frequently not pathologic IA non-small cell lung cancer: the problem of understaging. J Thorac Cardiovasc Surg. 2009;137:13-9.

27. Winton T, Livingston R, Johnson D, Rigas J, Johnston M, Butts C, et al; National Cancer Institute of Canada Clinical Trials Group; National Cancer Institute of the United States Intergroup JBR.10 Trial Investigators. Vinorelbine plus cisplatin vs. observation in resected non-small cell lung cancer. $N$ Engl J Med. 2005; 352:2589-97.

28. The International Adjuvant Lung Cancer Trial Collaborative Group. Cisplatin based adjuvant chemotherapy in patients with completely resected non-small cell lung cancer. $N$ Engl J Med. 2004;350:351-60.

29. Darling GE, Allen MS, Decker PA, Ballman K, Malthaner RA, Inculet RI, et al. Randomized trial of mediastinal lymph node sampling versus complete lymphadenectomy during pulmonary resection in the patient with N0 or N1 (less than hilar) non-small cell carcinoma: results of the American College of Surgery Oncology Group Z0030 Trial. J Thorac Cardiovasc Surg. 2011;141:662-70.

30. Wei B, Bryant AS, Minnich DJ, Cerfolio RJ. The safety and efficacy of mediastinoscopy when performed by general thoracic surgeons. Ann Thorac Surg. 2014;97:1878-84

31. Witte B, Wolf M, Huertgen M, Toomes H. Video-assisted mediastinoscopic surgery: clinical feasibility and accuracy of mediastinal lymph node staging. Ann Thorac Surg. 2006;82:1821-7.

32. Zielinski M, Szlubowski A, Kołodziej M, Orzechowski S, Laczynska E, Pankowski J, et al. Comparison of endobronchial ultrasound and/or endoesophageal ultrasound with transcervical extended mediastinal lymphadenectomy for staging and restaging of non-small-cell lung cancer. J Thorac Oncol. 2013;8: 630-6.

33. Silvestri GA, Gonzalez AV, Jantz MA, Margolis ML, Gould MK, Tanoue LT, et al. Methods for Staging Non-small Cell Lung Cancer: Diagnosis and Management of Lung Cancer, 3rd ed: American College of Chest Physicians EvidenceBased Clinical Practice Guidelines. Chest. 2013;143(5 Suppl):e211S-50S.
34. Yasufuku K, Pierre A, Darling G, de Perrot M, Waddell T, Johnston M, et al. A prospective controlled trial of endobronchial ultrasound-guided transbronchial needle aspiration compared with mediastinoscopy for mediastinal lymph node staging of lung cancer. J Thorac Cardiovasc Surg. 2011;142:1393-400.

\section{Discussion}

Dr Jay Lee (Los Angeles, Calif). The authors present their work in a multicenter prospective trial in which clinical stage T2N0 and a high-risk population with T1N0 defined by a maximum SUV greater than 10 were evaluated with the hope that the utility of routine mediastinoscopy to identify occult mediastinal metastases could be identified and defined. The conclusion is that there seems to be limited utility of routine mediastinoscopy in patients with $\mathrm{T} 1$ and $\mathrm{T} 2$ disease who are staged with NO by PET-CT.

I have several questions. It appears that positive N2 lymph nodes occurred in patients with tumors that were approximately $3 \mathrm{~cm}$ or larger, but your conclusion is that in a patient with T2N0, there is little utility for mediastinoscopy. Can you comment on that, given that the majority of your positive $\mathrm{N} 2$ lymph nodes were in the larger tumors?

Dr Fernandez. There were 4 patients with clinical T2 status who had a positive N2 lymph node, so that is a rate of $4.4 \%$, and actually only 1 patient who would be categorized as T1N0 with a high SUV, so that was actually a little higher rate of $11 \%$. For the entire cohort, the mean tumor size was 4.3 and the mean SUV was 13, and in the N2-positive patients, the mean tumor size was $3 \mathrm{~cm}$ and the mean SUV was 10 . Our data do not show that bigger tumors or higher SUVs were correlated in any way with N2 disease.

Dr Lee. There are variations in SUV measurements that are well known and reported in the literature. In fact, there are interobserver variations, interscanner, interinstitutional, and intrapatient variations. There are studies that show that when PET scans are done at different time intervals in a short period, there are variations in the SUV measurements. How did you standardize, control, and deal with that issue, particularly across 5 different institutions?

Dr Fernandez. Right. I completely agree with you. An SUV at my institution is different than one at yours. That is a limitation of our study. We didn't control for that, and it is difficult to control for that, particularly with our study design. This more reflects the clinical practice that we each have. It's hard to say precisely that an SUV of 10 at one institution is an SUV of 10 at another.

Dr Lee. How many of your cancers were composed of a mixed solid and ground-glass component that defined the size of the tumor, and did you look at those tumors as being defined by the solid component or did you take the total size of the tumor itself in defining T2?

Dr Fernandez. We took the total size of the tumor. We did not break it up into the ground-glass and solid component. Certainly that would be of interest in further analyses perhaps with larger datasets.

Dr Scott Swanson (Boston, Mass). I saw half VATS, half thoracotomy, early-stage cancer. Do you have any idea why you didn't have a higher prevalence of VATS operations? Related to that, do you know if the upstaging was any different in the VATS versus the thoracotomy group? 
Dr Fernandez. With regard to whether upstaging was greater with VATS or thoracotomy, I don't know that, but we should look into that. That is a good question. The surgical approach is what the surgical approach is. We recorded it. There were 6 pneumonectomies. There were some sleeves and some bilobectomies.

Dr Swanson. You had 80 lobectomies.

Dr Fernandez. That is correct.

Dr Swanson. What percentage were done by VATS, do you know?

Dr Fernandez. Of those lobectomies, I would have to go back to tell you, but you are correct, of the entire cohort, $44 \%$ of the cases were done by VATS.

Dr John Howington (Evanston, Ill). Nine patients received a mediastinoscopy and went on to resection, and they did not have cancer. Were all of those clinical T1s that had a high SUV or were any of those larger tumors? Second, how many of those granulomas that were resected were done by a thoracotomy?

Dr Fernandez. Nine patients did not have lung cancer; 5 had benign conditions (organizing pneumonias, granulomas), and 4 actually did have other malignancies. There was a metastatic breast cancer, choriocarcinoma, thymoma, and lymphoma. So 4 of those other ones were malignancies, but not lung cancers. I would have to go back and break down that group in terms of size, SUV, and surgical approach.

Dr David Harpole (Durham, $N C$ ). I have 2 points. Number one, it looked like approximately half of your patients had squamous carcinomas, which is a little unusual in the population, and we tend to see squamous carcinomas with larger tumors. That may have been the reason you had that bias. We also note that with squamous cell carcinomas, there is a lower incidence of mediastinal nodal involvement. Although your numbers are small, did you look at the difference between adenocarcinoma and squamous for the cell type and see if it might skew your results? We all tend to be more concerned about a larger adenocarcinoma with occult N2 disease. Have you looked at that?

Dr Fernandez. We did. There were only 2 adenocarcinomas with N2 disease, and that was approximately 5\%, and about the same as squamous cell cancers. I agree with you that we would need a larger sample size to do that. Not all of our tumors had a tissue diagnosis before going to the operating room. Although tumor histology is important, it is hard to prospectively look at that before you take the patient to the operating room.

Dr Harpole. The only other comment that I will make is that the original article by Meyers and colleagues ${ }^{14}$ looked at the cost of mediastinoscopy as an isolated event, and the majority of us do these as bronchoscopy, mediastinoscopy, lobectomy as one continual event, which adds approximately 30 minutes of operating room time, and the way Medicare reimburses, it's $100 \%$ of the large fee, $50 \%$ of the second fee, $25 \%$ of the third fee, and less than that for the fourth. So for bronchoscopy and mediastinoscopy, the incremental cost is actually small. If you are going to remodel it, you probably ought to look at it that way, and those of us who do it don't look at it from a cost-benefit thing as being quite as much as if you do it in an isolated setting.

Dr Todd Demmy (Buffalo, NY). I have 2 questions. First, quality control. I noticed that a $2 \mathrm{R}$ node was found in only $55 \%$ of the cases. Were they doing video mediastinoscopy? When you went back through the cases, how did you reconcile level 7 for the 2 pneumonectomies where it was found by the thoracotomy but not by the mediastinoscopy? Did you go back and review those cases for quality at the institutions and reasons mediastinoscopy missed?

Dr Fernandez. We required that 3 lymph nodes be sampled as a minimal guideline, to set a minimal standard. Again, this was a pragmatic study. Other than the 3 lymph node stations being required, there weren't any other tighter specifications. It would be worthwhile to go back and look at those that were positive and see if staging could have been better in those.

Dr Demmy. For selection bias, 5 institutions, 5 years, there should be a lot more patients than 90 . This seems like it would be an easy trial to accrue to. Why was there an issue with accrual in this study, and could that have affected your results?

Dr Fernandez. It's hard to know if that could have affected our results. This study was done as a collaboration of many surgeons, without the funding or support of a collaborative group. All of the logistic efforts were made on our own initiative. The recruitment was a little slower at first, but we were able to complete the study. 
TABLE E1. Complications associated with pulmonary resection ( $n=95$, includes resections performed for benign disease or other malignancy)

\begin{tabular}{lc}
\hline \multicolumn{1}{c}{ Complication } & No. $(\%)$ \\
\hline Mortality & $2(2.1)$ \\
Atrial fibrillation & $10(10.5)$ \\
Prolonged air leak & $8(8.4)$ \\
Reintubation & $7(7.4)$ \\
Pneumonia & $7(7.4)$ \\
Tracheostomy & $6(6.3)$ \\
Bronchoscopy & $6(6.3)$ \\
Transfusion & $5(5.3)$ \\
Renal failure & $4(4.2)$ \\
Return to operating room & $3(3.2)$ \\
ARDS & $2(2.1)$ \\
Intraoperative hemorrhage & $2(2.1)$ \\
Bronchopleural fistula & $1(1.1)$ \\
Hemothorax & $1(1.1)$ \\
Chylothorax & $1(1.1)$ \\
Wound infection & $1(1.1)$ \\
\hline ARDS, Acte resira
\end{tabular}

ARDS, Acute respiratory distress syndrome. 